\title{
Gêneros Textuais, Material Didático e Formação de Professores"
}

Vera Lúcia Lopes CRISTOVÃO

Universidade Estadual de Londrina

Resumo: Este trabalho tem como objetivo apresentar uma análise inicial do processo de elaboração de atividades didáticas em torno de gêneros textuais em um projeto de extensão com a participação de professores colaboradores e alunos-professores. A base teórica e metodológica do trabalho se centra no interacionismo sociodiscursivo (BRONCKART, 1999; DOLZ \& SCHNEUWLY, 1998) e nas considerações dessa corrente teórica da psicologia sobre aprendizagem de capacidades de linguagem (DOLZ \& SCHNEUWLY, 1998). Além de uma avaliação preliminar de uma primeira unidade didática elaborada pelos participantes do referido projeto, os resultados pretendem apontar para a necessária discussão da relação entre elaboração de material didático e a formação/o desenvolvimento profissional dos sujeitos envolvidos.

Palavras-chave: gêneros textuais; material didático; formação de professores

Abstract: In this article we aim at presenting an initial analysis of the production of didactic activities around textual genres by teachercollaborators and student-teachers who participate in a university project. The theoretical and methodological construct is based on the sociodiscoursive interactionism (BRONCKART, 1999; DOLZ \& SCHNEUWLY, 1998) and on the considerations of this theoretical psychological paradigm about the learning of language capacities (DOLZ \& SCHNEUWLY, 1998). Besides a preliminary evaluation of the first didactic sequence produced by the participants of the project, the results aim at indicating the necessary discussion of the relation between the production of didactic material and the professional development/ education of the ones involved.

\footnotetext{
${ }^{1}$ Trabalho apresentado no Congresso Brasileiro de Lingüística Aplicada em 2005.
} 
Key words: textual genres; didactic material; teacher education

Resumen: Este trabajo tiene como objetivo presentar un análisis inicial del proceso de elaboración de actividades didácticas en torno a los géneros textuales en un proyecto de formación continuada con la participación de profesores colaboradores y alumnos-profesores. La base teórica y metodológica del trabajo se centra en el interaccionismo sociodiscursivo (BRONCKART, 1999; DOLZ; SCHNEUWLY, 1998) y en sus consideraciones de esa corriente teórica de la sicología sobre aprendizaje de capacidades de lenguaje (DOLZ \& SCHNEUWLY, 1998). Además de una evaluación preliminar de una primera unidad didáctica elaborada por los participantes del referido proyecto, los resultados pretenden señalar hacia la a necesaria discusión de la relación entre elaboración de material didáctico y la formación / o desarrollo profesional de los sujetos involucrados.

Palabras-clave: géneros textuales; material didáctico; formación de profesores.

\section{Introdução}

A imagem do professor como um executor do trabalho educacional tem sido largamente tratada tanto em textos prescritivos (BRASIL, 1999) quanto em muitos relatos de pesquisa que investigam a ação docente (PERFEITO, 2003). Há ampla difusão acerca da docência enquanto uma ação de realização do que é pensado, elaborado e decidido pelo outro, como no caso das deliberações produzidas pelos agentes superiores do sistema educacional e mesmo de ensino, cabendo aos participantes do sistema didático a implementação do trabalho. Este trabalho pretende destacar o papel oposto do profissional da educação enquanto criador, elaborador e produtor de conhecimento.

Em um primeiro estudo, o Projeto de Pesquisa Modelos Didáticos de Gêneros: uma abordagem para o ensino de LE, desenvolvemos a análise de gêneros textuais que podem atravessar os objetos de ensino no fundamental. Assumimos a definição de gênero na qual Bronckart (1999,p.73) reforça a estreita inter-relação de texto com o contexto. 


\begin{abstract}
... na noção de gênero de texto no decorrer deste século e, mais particularmente a partir de Bakhtin, essa noção tem sido progressivamente aplicada ao conjunto das produções verbais organizadas: às formas escritas usuais (artigo científico, resumo, notícia, publicidade, etc.) e ao conjunto das formas textuais orais, ou normatizadas, ou pertencentes à 'linguagem ordinária'(exposição, relato de acontecimentos vividos, conversação, etc). Disso resulta que qualquer espécie de texto pode atualmente ser designada em termos de gênero e que, portanto, todo exemplar de texto observável pode ser considerado como pertencente a um determinado gênero.'
\end{abstract}

Assim, concordamos com Schneuwly e Dolz (2004, p. 72-73) em relação ao papel dos gêneros de articularem as práticas sociais de linguagem aos objetos de ensino. "As práticas de linguagem implicam tanto dimensões sociais como cognitivas e lingüísticas do funcionamento da linguagem numa situação de comunicação particular." Desse modo, a compreensão e produção de textos demanda a aprendizagem de capacidades de linguagem. Estas, segundo Dolz, Pasquier \& Bronckart (1993) e Dolz \& Schneuwly (1998), seriam de três tipos:

a) as capacidades de ação, isto é, o reconhecimento do gênero e de sua relação com o contexto de produção e mobilização de conteúdos;

b) as capacidades discursivas, isto é, o reconhecimento do plano textual geral de cada gênero, os tipos de discurso e de seqüência mobilizados;

c) as capacidades lingüístico-discursivas, isto é, o reconhecimento e a utilização do valor das unidades lingüístico-discursivas inerentes a cada gênero para a construção do significado global do texto.

As capacidades de linguagem que poderão ser desenvolvidas a partir do trabalho com os textos serão apontadas a partir dos modelos didáticos de gêneros construídos no projeto de pesquisa supracitado. Para a construção de um modelo didático do gênero, deve-se, portanto, conhecer o estado da arte dos estudos sobre ele, incluindo suas características lingüísticas e textuais; as capacidades e as dificuldades dos alunos em se trabalhar com textos do gênero 
selecionado e as experiências de ensino/aprendizagem oriundas de documentos oficiais além da análise de corpora de textos pertencentes ao gênero (DOLZ; SCHNEUWLY, 1998). Esses pontos ajudam a definir a intervenção didática e a construir o modelo. Isso permite definir os objetivos do ensino do gênero adaptados ao nível dos alunos e organizar as categorias que devem ser exploradas em um material didático.

Entre as considerações dessa pesquisa, destacamos a precariedade das condições de ensino-aprendizagem das práticas de uso da linguagem. Os professores de inglês da educação básica têm que superar grandes dificuldades para transpor o conhecimento científico para conhecimento a ser ensinado e, finalmente, para a prática pedagógica. As transformações (transposição didática) ocorridas nesse processo exigem uma reorganização da própria ação dos participantes desses sistemas de ensino para a intervenção imediata ou prognóstica. Isso nos levou a realização de um projeto de extensão "Materiais Didáticos para o ensino de inglês para a educação básica" com uma equipe de alunos-professores e professores-colaboradores com o objetivo de elaborar material didático que atenda as necessidades do contexto ao mesmo tempo em que venha a romper com a linha tradicional de foco no ensino da gramática.

Nosso novo estudo tem como objetivos: a) avaliar a primeira unidade (material didático) produzida no projeto; b) avaliar a proposta de trabalho com a gramática e o perigo da gramaticalização do gênero e c) identificar o agir dos trabalhadores do ensino em seu desenvolvimetno profissional. Para isso, discorreremos, a seguir, sobre alguns conceitos fundamentais, detalhamos a metodologia, apresentamos os resultados e discutimos suas implicações.

\section{Interacionismo sociodiscursivo (ISD)}

O foco nas ferramentas de ensino trazendo à tona a questão da produção de materiais de ensino se justifica por vários motivos e, dentre eles, a preocupação com a intervenção na educação e a necessidade da relação teoria-prática. Com isso, não estamos deixando em segundo plano a necessidade das pesquisas com a análise do desenvolvimento e aprendizagem; da interação professor - 
ferramenta - aluno e dos processos de formação de professores. Estamos priorizando o foco nas ferramentas em consonância com a preocupação de que as ferramentas usadas na interação sejam mais do que artefatos que possibilitam a realização de uma tarefa agindo sobre o objeto, mas que venham a ser instrumentos que agem sobre o sujeito para seu desenvolvimento (CLOT, 2004).

O trabalho de Machado (2004) apresenta o construto teórico em torno do conceito de gênero, fundamentado nas teorias e autores principais subjacentes ao ISD (Psicologia da Linguagem; Didática de Línguas e três grandes autores - Vygotsky, Bakhtin e Habermas) e nas definições de termos centrais para a interpretação do ISD e da relação de gênero com atividade, ação de linguagem e texto. Dentre esses termos, retomando Bronckart (1999), a autora mostra que, nessa corrente, texto é definido como "toda unidade de produção verbal, oral ou escrita, contextualizada, que veicula uma mensagem lingüisticamente organizada e que tende a produzir um efeito de coerência no seu destinatário" (BRONCKART, 1999, p. 5) e "Gênero de texto é aquilo que sabemos que existe nas práticas de linguagem de uma sociedade" (BRONCKART, 1999, p. 6). Em suas conclusões, a autora defende que "O objeto real de ensino e aprendizagem, portanto, seriam as operações de linguagem necessárias para essas ações, operações essas que, dominadas, constituem as capacidades de linguagem" (BRONCKART, 1999, p. 28). Em virtude da discussão sobre o risco da gramaticalização, destacamos as capacidades lingüístico-discursivas que "envolveriam os mecanismos de textualização, incluindo-se aí as operações de conexão e segmentação, de coesão nominal e verbal; os mecanismos enunciativos, que envolvem as operações de distribuição de vozes e de expressão de modalizações, e, enfim, em um nível mais micro, a construção dos enunciados e a escolha de itens lexicais" (MACHADO, 2001, p. 140).

Algumas das operações de linguagem que os alunos devem aprender dizem respeito à gramática. Sendo a língua tanto usada como instrumento de comunicação como de representação da realidade, o ensino deveria dar conta de proporcionar aos alunos o desenvolvimento das capacidades de comunicação oral e escrita bem como o desenvolvimento do conhecimento estrutural do sistema da língua (BRONCKART, SZNICER 1990). Servimo-nos da definição de 
gramática de Brakling (1999) como "o estudo dos processos que relacionam as expressões das línguas naturais à significação: o estudo gramatical procura responder por que as expressões significam aquilo que significam". Esse processo de significação envolve o sistema da língua que é mais complexo que um rol de estruturas sintáticas. Ele envolve conhecimentos sobre: a) vocabulário; b) adequação e estilo; c) sintaxe; d) fonologia; gramática e morfologia; e) gêneros textuais, organização textual e convenções discursivas; f) pragmática. Este estudo pretende analisar a relação do ensino de operações de linguagem relativas à gramática com gêneros textuais e formação de professores.

\section{Elaboração de material didático}

O ensino de língua estrangeira envolve uma série de variáveis que determinam nossa prática pedagógica. Segundo Schneuwly (1994), a prática da sala de aula é constituída pelo sistema didático formado pelo professor, pelos alunos e pelo objeto do conhecimento. Esse objeto se materializa por meio de diferentes recursos, a saber: a) material didático, b) fitas de áudio, c) fitas de vídeo, d) textos autênticos (didatizados), e) textos didáticos, f) ilustrações etc. Considerando esse sistema tripolar da sala de aula (professor-aluno-objeto de conhecimento), o material didático tem uma função de extrema importância, na medida em que, muitas vezes, é ele o único referencial do professor em sua ação pedagógica (SOUZA, 1999; ROJO, 2000).

O trabalho de Cunningsworth (1995, p. 7) discorre especificamente sobre material didático de língua estrangeira. Segundo o autor, os papéis do material didático são os seguintes: "um recurso para apresentação de material (oral e escrito); uma fonte de atividades para a prática do aprendiz e interação comunicativa; uma fonte de referência para alunos quanto à gramática, ao vocabulário, à pronúncia etc; uma fonte de incentivo e idéias para atividades de linguagem em sala de aula; um currículo (onde se refletem os objetivos de aprendizagem já determinados); um recurso para aprendizagem autodirecionada ou trabalho de auto-acesso; um suporte para professores menos experientes que ainda precisam ganhar em confiança." Concordamos com Cunningsworth, acrescentando ainda que, freqüentemente, o material didático é o único meio de interação com 
a língua estrangeira, a única fonte de atividades e referência. Além disso, no que se refere ao papel do material como uma concretização do currículo, é necesssário relacioná-lo às orientações propostas nos documentos nacionais para a educação básica.

Em língua estrangeira, as pesquisas de Coracini (1995; 1999) têm se voltado para questões relativas ao ensino e ao uso de livro didático e de textos em sala de aula. Em um desses trabalhos, Souza (1995) sugere que o livro didático (a principal fonte de material didático) usado em escolas do ensino fundamental e médio da rede oficial de ensino vinha sendo comumente concebido por professores e alunos como o apresentador de verdades e respostas que serão transmitidas aos seus usuários. Mais recentemente, a situação descrita pela autora aponta para um olhar mais crítico do professor em relação ao livro didático. Apesar disso, o profissional continua se posicionando como despreparado para fazer uma avaliação e adaptação do material didático.

Quanto ao ensino de gêneros, a preocupação foi evidenciada no simpósio: os gêneros textuais na formação dos professores: o perigo da gramaticalização dos gêneros, realizado no Congresso Brasileiro de Lingǘstica Aplicada em 2005.

Já com essa preocupação, Machado (2001) apresenta um instrumento de avaliação de material didático com base nas capacidades de linguagem a serem desenvolvidas no aprendizado. No trabalho desenvolvido no doutorado (CRISTOVÃO, 2002), defendi que o próprio modelo didático poderia ser um instrumento de avaliação. Assim, servimo-nos da proposta de análise das atividades à luz das capacidades de linguagem. Também adaptamos de Brakling (1999) categorias gerais de avaliação para análise das possibilidades de avanços na aprendizagem e de Brakling (2003, p. 215-216) categorias especificamente relacionadas aos conteúdos gramaticais.

\section{Metodologia}

\subsection{Descrição do projeto}

O projeto de elaboração de material didático para Educação Básica pretende proporcionar aos participantes a 
oportunidade de construir conhecimentos e estabelecer princípios para que o professor em serviço e os futuros professores possam produzir materiais didáticos de maneira informada, voltada para o exercício da cidadania e para a interdisciplinaridade e interculturalidade. As etapas prevêem: a) Discussão acerca do contexto de ensino (condições da escola, condições sócio-econômico-culturais, materiais empregados nos níveis fundamental e médio, exames de admissão para o ensino superior) e dos PCN; Leituras; Discussão de textos teóricos; b) Seleção de textos; Elaboração de materiais. c) Aplicação do material didático; Observação de aulas; d) Análise crítica do material aplicado; e) Divulgação dos resultados do projeto.

\subsection{Descrição dos participantes}

(1) Coordenadora - professora universitária há 11 anos, doutoranda da mesma universidade, membro do grupo de pesquisa em formação de professores e coordenadora de um projeto de pesquisa sobre o trabalho dos formadores. Já publicou material didático para a Educação Básica.

(1) Supervisora - professora universitária há 8 anos, doutora pelo LAEL - PUC-SP, membro do grupo de pesquisa de formação de professores, coordenadora de um projeto de pesquisa sobre gêneros textuais e do programa de extensão Núcleo de Assessoria Pedagógica (NAP) ao qual pertence o projeto de materiais. Já publicou material didático para a Educação Básica.

(6) Professores colaboradores -5 professoras de escolas públicas de Londrina, formadas em Letras Anglo-Portuguesa, tendo entre 3 e 9 anos de experiência. 4 têm pós-graduação Lato Sensu e 1 está cursando o Mestrado na instituição. 1 colaborador é funcionário da instituição, membro do projeto de pesquisa da supervisora e professor.

(3) Alunas-professoras do $4^{\circ}$ ano do curso de Letras Anglo-Portuguesa da universidade.

\subsection{Descrição da unidade Olympic Games}

A unidade é proposta em torno do tema Jogos Olimpicos e ênfase na compreensão escrita em inglês com uma notícia, uma 
reportagem e uma canção tema. Para iniciar a aula, sugere-se uma troca de informações, fontes de acesso de conhecimentos e notícias sobre o tema.Também questionam-se as diferenças entre reportagens de diferentes meios de veiculação. Em seguida, há uma notícia sobre as Olimpíadas retirada da internet (yahoo.news). O primeiro exercício pede as características desse tipo de texto com base em conhecimento prévio. Na próxima atividade, os alunos devem prever o conteúdo da notícia a partir de algumas palavras-chave dadas pelo professor. Depois de feitas as hipóteses, os alunos desenvolvem uma leitura rápida para confirmação ou refutação das suposições. $\mathrm{Na}$ seqüência, os exercícios partem para uma exploração mais detalhada da compreensão. $\mathrm{O}$ exercício dois é composto de duas perguntas sobre a manchete da notícia e uma da seção em que o texto aparece inserido. Também é solicitado que o aluno volte ao primeiro exercício sobre as características da notícia para confirmar ou não sua aplicabilidade à notícia lida.

De forma semelhante ao primeiro exercício, há uma atividade em que o aluno escolhe as alternativas referentes às características de uma reportagem. Na seqüência, há três alternativas de atividades que propõem o envolvimento do aluno com a leitura do texto. Primeiramente, solicita-se a análise da manchete de uma reportagem para prever-se o assunto e escrever umas palavras-chave. A leitura do texto é acompanhada de uma análise descritiva do texto (manchete, fonte, gênero, tema, público-alvo, emissor, momento histórico, espaço social, objetivo, componentes lingüísticos centrais), de organização textual (plano textual global) e atividades orais e/ou escritas que envolvem inferência, busca de informação, compreensão detalhada, paráfrase de idéias principais, leitura crítica e opinião pessoal. Há uma proposta de exercício de gramática em que se chama a atenção para a forma no uso do futuro.

O sentido da música é primeiramente explorado quanto ao seu vocabulário com base nos pares adjacentes do refrão, a fim de que o aluno possa, em seguida, ler o texto de apresentação da canção e destacar a idéia principal de cada parágrafo. Então, sugere-se que os alunos discutam em grupos o significado da passagem da Tocha Olímpica e leiam a letra da canção explorando as características do texto (refrão, versos, estrofes, repetições) e o uso do imperativo (recurso que causa um sentimento de obrigação que deve ser cumprida). 
Como um fechamento da unidade, sugere-se um trabalho de organização de vocabulário associado às categorias countries, cities, islands, natural features, Olympic Games, sports, emotions/ideals e uma brincadeira de bingo.

\subsection{Procedimentos de coleta}

Além da unidade produzida, pude contar com dois questionários respondidos no primeiro dia do projeto e com diários feitos no dia da síntese e avaliação.

\subsection{Procedimentos de análise}

O primeiro procedimento foi a descrição da unidade elaborada e uma análise global a partir dessa descrição. Em nossa pesquisa anterior, consideramos que o modelo didático de gênero poderia se constituir enquanto indicador de critérios de avaliação de material, e, conseqüentemente, da sua adequação ao desenvolvimento das capacidades de linguagem envolvidas. As atividades foram avaliadas, tomando como critério o tipo de capacidade que cada uma implica.

Em virtude da unidade estar organizada em torno de um tema com o uso de três gêneros textuais, servimo-nos de categorias mais gerais, adaptando os critérios de avaliação propostos por Brakling (1999) para verificarmos se as atividades propõem que o aluno:

1) demonstre compreensão de textos escritos em diferentes gêneros;

2) atribua sentido a textos escritos, posicionando-se criticamente;

3) leia de maneira independente;

4) estabeleça relações entre textos diretamente implicados;

5) selecione procedimentos de leitura adequados a diferentes objetivos e interesses e a características do gênero e suporte;

6) articule informações textuais com conhecimentos prévios e com o funcionamento da linguagem;

7) compreenda a função discursiva de unidades lingüísticas que caracterizem o gênero e sua relação com o contexto bem como seu papel na construção de sentido. 
Em relação ao trabalho com conhecimentos lingüísticos,com base em Brakling (2003), objetiva-se avaliar se o material por meio das atividades sugeridas procura: a) desenvolver o uso da língua; b) refletir sobre o uso da língua; c) construir conceitos e conhecimentos morfológicos, sintáticos, semânticos, pragmáticos/ discursivos e textuais.

\section{Análise e Discussão}

Segundo dados obtidos em um questionário inicial e pela própria apreciação geral da unidade, podemos apresentar algumas de suas características centrais.

O material produzido está voltado para aprendizes do Ensino Médio e, em alguns casos, Fundamental, majoritariamente para alunos de escolas públicas (de classe média-baixa), de salas numerosas, sem livro didático e com expectativa de ter chance de ingresso em Instituição de Ensino Superior pública pela aprovação no vestibular da universidade pública da cidade. Os participantes do projeto esperam poder elaborar atividades que propiciem motivação, reflexão e possibilidade de realização e adaptação. A ênfase desejada é na leitura voltada para "exercício da cidadania, aquisição de autonomia, desenvolvimento das capacidades lingüísticas e ensino da gramática de língua inglesa".

A primeira unidade não traz explicitado o objetivo geral, mas a discussão de seus pontos relevantes em uma das reuniões com o grupo revelou a preocupação com a seleção de textos de diferentes gêneros, as características dos gêneros abordados e o conteúdo em língua inglesa a que os alunos estariam expostos.

Com relação ao conteúdo, a unidade está organizada em torno de um tema - Jogos Olímpicos com diferentes aspectos sendo abordados: contexto, organização, estilo, estrutura composicional, tema, funções, vocabulário e gramática. Nesse sentido, entendemos que a linguagem posta como objeto de ensino está sendo tomada em uma perspectiva de discurso. A relação com seu contexto social e função apresenta referências explícitas em diferentes atividades ao longo da unidade. Além disso, o conteúdo procura promover variedade de gêneros e tópicos dentro do tema escolhido. 
As atividades propostas variam de controladas e não-controladas para a avaliação das capacidades que envolvem a compreensão escrita (operações de inferência, dedução, mobilização de conhecimento prévio, memória etc).

Quadro 1 - Avaliação da unidade em relação às capacidades de linguagem

\begin{tabular}{|c|c|c|c|}
\hline $\begin{array}{l}\text { Capacidades } \\
\text { de } \\
\text { linguagem }\end{array}$ & Conteúdo explorado & $\begin{array}{l}\text { Conteúdo das atividades da } \\
\text { unidade }\end{array}$ & $\begin{array}{l}\text { Exemplo de atividade ou } \\
\text { justificativa }\end{array}$ \\
\hline $\begin{array}{l}\text { Capacidade } \\
\text { de ação }\end{array}$ & $\begin{array}{l}\text { Representações sobre a } \\
\text { situação e à mobilização } \\
\text { de conteúdos }\end{array}$ & $\begin{array}{l}\text { Perguntas que exploram o } \\
\text { contexto de produção dos } \\
\text { textos }\end{array}$ & $\begin{array}{l}\text { De onde foi retirado o texto? } \\
\text { Para quem ele foi escrito? }\end{array}$ \\
\hline $\begin{array}{l}\text { Capacidade } \\
\text { discursiva }\end{array}$ & $\begin{array}{l}\text { Plano geral do texto, tipos } \\
\text { de discurso e tipos de } \\
\text { seqüência }\end{array}$ & $\begin{array}{l}\text { Exercício de identificação das } \\
\text { características de notícia e } \\
\text { reportagem }\end{array}$ & $\begin{array}{l}\text { Assinale alternativas condizentes } \\
\text { a uma reportagem. }\end{array}$ \\
\hline $\begin{array}{l}\text { Capacidade } \\
\text { lingüístico- } \\
\text { discursiva }\end{array}$ & $\begin{array}{lcl}\text { Questões } & \text { relativas } & \text { à } \\
\text { coesão, à } & \text { conexão, } & \text { à } \\
\text { modalização } & \mathrm{e} & \text { à } \\
\text { distribuição das vozes } & \end{array}$ & $\begin{array}{l}\text { Exercício de vocabulário e de } \\
\text { tempo verbal }\end{array}$ & $\begin{array}{l}\text { Organização de vocabulário } \\
\text { associado às categorias } \\
\text { countries, cities, islands, natural } \\
\text { features, Olympic Games, sports, } \\
\text { emotions/ideals. }\end{array}$ \\
\hline
\end{tabular}

Como pudemos mostrar no quadro 1, diferentes atividades procuraram contemplar algum conteúdo referente à aprendizagem de capacidades de linguagem. Contudo, a meu ver, o trabalho não deu conta de todas operações necessárias para uma leitura crítica.

Com base na adaptação dos critérios propostos por Brakling (1999), fizemos a avaliação desse material, como demonstra o quadro 2. 
Quadro 2 - Avaliação geral da unidade

\begin{tabular}{|c|c|c|}
\hline Critério & $\mathrm{X}$ ou $\varnothing$ & Exemplo de atividade ou justificativa \\
\hline $\begin{array}{l}1 \text { - demonstre compreensão de } \\
\text { textos escritos em diferentes } \\
\text { gêneros }\end{array}$ & $\mathbf{X}$ & $\begin{array}{l}\text { A notícia é um tipo de texto que tem características } \\
\text { diferenciadas dos demais. Assinale alternativas condizentes a } \\
\text { uma noticia. }\end{array}$ \\
\hline $\begin{array}{lr}2-\text { atribua } & \text { sentido a textos } \\
\text { escritos, } & \text { posicionando-se } \\
\text { criticamente } & \end{array}$ & $\mathbf{X}$ & $\begin{array}{l}\text { Para você, quais devem ser os ideais de uma Olimpiada? } \\
\text { Discutir nos grupos os vários interesses que movem a } \\
\text { passagem da Tocha por tantos lugares e a importância dessa } \\
\text { passagem para o momento histórico. }\end{array}$ \\
\hline 3 - leia de maneira independente & $\begin{array}{l}\text { Parcial- } \\
\text { mente já } \\
\text { que é } \\
\text { optativo }\end{array}$ & $\begin{array}{l}\text { Se for dado outro texto, pedir para cada grupo expor } \\
\text { idéias sobre o texto, explicar o que leram, e identificar o que } \\
\text { bá de semelhante entre os dois textos. }\end{array}$ \\
\hline $\begin{array}{l}4 \text { - estabeleça relações entre } \\
\text { textos diretamente implicados }\end{array}$ & $\varnothing$ & $\begin{array}{l}\text { Apesar da relação entre a reportagem e a letra da } \\
\text { canção, não há uma orientação de articulação entre } \\
\text { os dois textos. }\end{array}$ \\
\hline $\begin{array}{l}5 \text { - selecione procedimentos de } \\
\text { leitura adequados a diferentes } \\
\text { objetivos e interesses e a } \\
\text { características do gênero e } \\
\text { suporte }\end{array}$ & $\begin{array}{l}\text { Parcial- } \\
\text { mente }\end{array}$ & $\begin{array}{l}\text { Os procedimentos são baseados na proposta de pré- } \\
\text { leitura, leitura e pós-leitura com objetivo de } \\
\text { compreensão detalhada. }\end{array}$ \\
\hline $\begin{array}{l}6 \text { - articule informações textuais } \\
\text { com conhecimentos prévios e } \\
\text { com o funcionamento da } \\
\text { linguagem }\end{array}$ & $\mathbf{X}$ & $\begin{array}{l}\text { O que você acha que o texto irá abordar? Escreva algumas } \\
\text { palavras-chave. }\end{array}$ \\
\hline $\begin{array}{l}7 \text { - compreenda a função } \\
\text { discursiva de unidades } \\
\text { lingüísticas que caracterizem o } \\
\text { gênero e sua relação com o } \\
\text { contexto bem como seu papel } \\
\text { na construção de sentido }\end{array}$ & $\varnothing$ & $\begin{array}{l}\text { As atividades propostas não especificam a } \\
\text { função discursiva das unidades selecionadas } \\
\text { (tempo verbal - simple past e simple future) } \\
\text { Enfocar o uso de verbo no passado no texto, } \\
\text { pedindo aos alunos que observem a função que } \\
\text { a forma ED tem aí; } \\
\text { Em seguida, enfocar o uso do WILL no texto }\end{array}$ \\
\hline
\end{tabular}

Podemos dizer, que, no material, são consideradas as especificidades de cada gênero e do suporte, mas há limitação quanto aos objetivos. Parece haver uma preocupação com o objetivo didático de compreensão do conteúdo especialmente veiculado pelas escolhas lexicais, em detrimento de uma leitura voltada para o objetivo do texto quando de sua circulação. Mesmo acreditando que todo gênero torna-se didatizado ou escolarizado a partir do momento em que é retirado de sua esfera de circulação para ser objeto de ensinoaprendizagem em sala de aula com objetivos didáticos específicos, as atividades podem problematizar a questão do contexto de circulação social do texto e o contexto didático de uso do mesmo para compreensão da situação de comunicação que envolvem o texto nas duas instâncias de leitura. Dessa forma, avalio como produtivas as atividades em que se busca representar as condições de produção dos textos. 
Se entendermos gramaticalização como um "engessamento" ou "encapsulamento" do gênero, avalio que esse material não cai nesse engessamento. Entretanto, ainda está distante do estudo contextualizado de gramática. Com isso, faço uma relação dessa avaliação a uma asserção de Possenti (1996, p. 84) sobre ensino de línguas estrangeiras, “... ensinavam-se as regras gramaticais dessas línguas e o resultado era invariavelmente a incapacidade dos alunos de as falarem. Não teria sido mais proveitoso ocorrer o inverso, isto é, que se aprendesse a falar essas línguas, ao invés de falar sobre elas?". Nessa relação, o professor e os alunos estariam preocupados com a compreensão para, então, estudar as características de linguagem associadas ao contexto (de produção e de leitura), servindo-se de unidades com função discursiva e não simplesmente a prática de formas sintáticas e memorização. O trabalho de análise lingüística está proposta ainda enfatizando a questão da forma. Há uma tentativa de identificação da função discursiva do item sendo estudado no exercício referente ao uso do imperativo na letra da canção. Sugere-se que o aluno pense a respeito do recurso sintático utilizado pelo compositor para convencer (uso de emoção) o ouvinte da mensagem.

Ao voltarmos ao conceito de gramática - a relação entre expressões da língua e significação, ressalta-se a importância do estudo de compreensão do funcionamento da linguagem a favor da construção de significado. Essa questão foi levantada e apontada como fonte de preocupação por pesquisadores e professores participantes do II Simpósio Nacional de Gêneros Textuais (SIGET). Tal inquietação nos leva ao segundo agrupamento de critérios proposto por Brakling (2003).

Conforme nos mostram os dados, observamos que as atividades procuram desenvolver o uso da língua e refletir sobre esse uso. A comparação entre notícia e reportagem e a análise do contexto de produção dos textos selecionados apontam para um objetivo de se incorporar aspectos relacionados ao uso da língua. Como não há maiores explicações sobre as características enfocadas e o quadro contextual, há um risco de generalização e não do tratamento de variantes de gênero. O risco da gramaticalização emerge, pois o gênero pode tanto ser um fator que restringe como um fator que liberta o autor, propiciando-lhe condições de autoria, criatividade e autonomia. Um enfoque no gênero como restrição ou como liberdade depende 
da atividade e da abordagem de ensino proposta. No caso analisado, os exercícios generalizam as características de cada texto para traços de notícia e reportagem, restringindo o que diferentes variantes do mesmo gênero possam apresentar. Se o aluno fosse exposto a variantes ou a um corpus claramente exposto, o sujeito teria mais condição de fazer suas articulações para construção de sentido e aprendizagem.

Quanto à gramática propriamente dita, privilegiam-se as definições à construção de conceitos e de conhecimentos. Apesar de alguns traços de trabalho com conhecimentos sintáticos, semânticos, pragmáticos/discursivos e textuais, o estudo nessa primeira unidade ainda é incipiente.

As características elencadas dos gêneros selecionados vieram da literatura consultada, da coordenadora e dos conhecimentos trazidos pelo colaborador, que faz parte do projeto de pesquisa de análise de gêneros. Em função da análise da unidade e dessa informação, ratifico a necessária articulação entre os dois projetos para que saibamos explorar adequadamente os objetos de ensino que elegemos como nossas ferramentas.

O processo de produção dessa primeira unidade se deu em um contexto de formação continuada. Diferentes atividades foram realizadas ao longo do processo, como pode ser observado no quadro 3.

Quadro 3 - Atividades relacionadas à elaboração da primeira unidade didática

\begin{tabular}{|l|l|l|}
\hline Data & $\begin{array}{c}\text { Responsá } \\
\text { vel }\end{array}$ & \multicolumn{1}{c|}{ Atividade } \\
\hline $28 / 05$ & Coord. & $\begin{array}{l}\text { Prá começo de conversa: levantamento de expectativas e } \\
\text { necessidades }\end{array}$ \\
\hline $11 / 06$ & Coord. & $\begin{array}{l}\text { Análise do vestibular da UEL } \\
\text { Implicações para produção de materiais }\end{array}$ \\
\hline $24 / 06$ & Coord. & $\begin{array}{l}\text { Discussão dos PCN LE - EM e EF, } \\
\text { Discussão de ROJO (Modos de transposição dos PCNs às } \\
\text { práticas de sala de aula: progressão curricular e projetos) } \\
\text { Implicações para produção de materiais }\end{array}$ \\
\hline $26 / 06$ & Coord. & Grupo de estudos \\
\hline $08 / 07$ & Coord. & Oficina de seleção de textos \\
\hline $23 / 07$ & Coord. & Oficina de seleção de textos e preparação de materiais \\
\hline $30 / 07$ & Coord. & Oficina de preparação de materiais \\
\hline $20 / 08$ & $\begin{array}{l}\text { Coord. e } \\
\text { Super. }\end{array}$ & Oficina de preparação de materiais \\
\hline $27 / 08$ & $\begin{array}{l}\text { Coord. e } \\
\text { Super. }\end{array}$ & Síntese e avaliação com produção de diário \\
\hline
\end{tabular}


A unidade analisada bem como a noção de gêneros de ensino na escola passaram por uma apreciação e discussão do grupo, que passo a ilustrar com alguns excertos dos diários de reunião.

Nessa reunião percebi como as diferentes questões que os participantes fazem contribuem para por em marcha minha compreensão. Ex: J. perguntou COMO a língua reflete através do gênero os padrões culturais e interacionais da comunidade. Isso me desafiou a ir procurar essa relação no texto.

O texto conceitua 'gênero', traz as várias visões dos estudiosos; levanta questões como o perigo de se cair na mesmice, ou, de acabar sendo usado como pretexto para o ensino de gramática ou vocabulário.

Duas questões foram levantadas e embora tenhamos discutido sobre as mesmas ainda não fechamos o assunto sobre elas:

a) Como trabalhar o contexto, que a meu ver é o diferencial entre o trabalho com o gênero e textos didáticos; sem esquecermos que nosso foco de ensino é a língua inglesa?

b) Como explorar os elementos culturais presentes nos textos?

Esses trechos revelam, a meu ver, uma postura crítica e reflexiva e uma preocupação com a não normatização do trabalho com gênero. O trabalho de elaboração de material didático por professores colaboradores por meio de sua participação em projeto de extensão universitária ilustra a reconhecida e importante relação ensino-pesquisa-extensão. Veiga (2004) defende que o processo didático implica em ensinar, aprender, pesquisar e avaliar. Esse projeto proporciona essa relação pedagógica articulada a partir do desenvolvimento das diferentes atividades e do uso do material no contexto escolar dos participantes. Tanto aplicação das atividades quanto sua avaliação podem ser instrumentos para avaliar as propostas e articular uma relação pedagógica com um compromisso social e educacional. Esse espaço de elaboração de material didático possibilita que o professor em exercício e o futuro profissional criem e produzam projetos didáticos e assumam seu papel de produtores de conhecimento. 


\section{Considerações Finais}

A avaliação da unidade nos revela uma proposta de trabalho que já se diferencia de um estudo centrado em pontos gramaticais. Além de uma preocupação com a leitura, as atividades procuram envolver o aluno com a língua inglesa como instrumento de comunicação e de representação da realidade.

O projeto também defende o trabalho do professor de planejar sua prática pedagógica e se responsabilizar pela produção de ferramentas que possam orientar suas ações docentes. Com isso, avalio que estamos trabalhando em favor da emancipação dos participantes alcançando práticas produtivas, críticas e reflexivas. O estudo de diferentes práticas de linguagem que se desenvolvem no trabalho educacional colabora para o aprofundamento das questões teóricas e metodológicas que subjazem nossas ações.

\section{Referências Bibliográficas}

BRÄKLING, K. L. A gramática nos LDs de $5^{a}$ a $8^{a}$ series: "que rio é este pelo qual corre o Ganges?” In: ROJO, R.; BATISTA, A . A. G. (Orgs.) Livro didático de língua portuguesa, letramento e cultura da escrita. Campinas: Mercado de Letras, 2003. p. 211-252.

Curso proferido na Pontifícia Universidade Católica de São Paulo em 1999.

BRASIL. Ministério da Educação. Secretaria de Educação Média e Tecnológica. Parâmetros curriculares nacionais: ensino médio. Brasília: MEC/SEMT, 1999. p. 25-32.

BRONCKART, Jean-Paul. Atividade de Linguagem, textos e discursos: por um interacionismo sócio-discursivo. Trad. Anna Rachel Machado; Pericles Cunha. São Paulo: Educ. 1999.

.; SZNICER, G. Description grammaticale et principes d'une didactique de la grammaire. Le français aujourd'hui, «Travailler la langue: nouvelles démarches», n. 89, p. 5-16, 1990. 
CLOT, Y. Comunicação oral proferida na Pontifícia Universidade Católica de São Paulo em 17 set. 2004.

CORACINI, Maria José Rodrigues Faria. (Org.) Interpretação, autoria e legitimação do livro didático. São Paulo: Pontes. 1999.

Pontes, 1995.

(Org.). O jogo discursivo na sala de leitura. São Paulo:

CRISTOVÃO, Vera Lúcia Lopes. Gêneros e ensino de leitura em LE: os modelos didáticos de gêneros na construção e avaliação de material didático. 2002. Tese (Pesquisa de doutorado) - Pontifícia Universidade Católica de São Paulo, São Paulo.

CUNNINGSWORTH, A. Choosing your Coursebook. Oxford: Macmillan/Heinemann, 1995.

DOLZ, Joaquim; NOVERRAZ, M.; SCHNEUWLY, Bernard. Seqüências didáticas para o oral e a escrita: apresentação de um procedimento. In: SCHNEUWLY, B.; DOLZ, J. (Orgs.) Gêneros orais e escritos na escola. Trad. Org. Roxane Rojo; Glais Sales Cordeiro. Campinas: Mercado de Letras, 2004. p. 95-128.

; SCHNEUWLY, Bernard. Pour un enseignement de l'oral. Initiation aux genres formels à l'école. Paris: ESF ÉDITEUR, 1998. (Didactique du Français).

; PASQUIER, Auguste; BRONCKART, Jean-Paul. L'acquisition des discours: emergence d'une competence ou apprentissage de capacities langagières? ÈLA - Études de Linguistique Appliquée, n. 92, p. 23-37, 1993.

MACHADO, A. R. O ensino como trabalho: uma abordagem discursiva. Londrina: EDUEL, 2004.

Um instrumento de avaliação de material didático com base nas capacidades de linguagem a serem desenvolvidas no aprendizado de produção textual. Intercâmbio, v. 10, p. 137-147, 2001.

MARCUSCHI, L. A. Gêneros Textuais: definição e funcionalidade. In: DIONISIO,A ; MACHADO, A . R.; BEZERRA, M. A (Orgs). Gêneros Textuais \& Ensino. Rio de Janeiro: Lucerna, 2002. p. 1936. 
MEURER, José Luiz. O Conhecimento de gêneros textuais e a formação do profissional da linguagem. In: FORTKAMP, Mailce Borges Mota; TOMITCH, Lêda Maria Braga (Org.) Aspectos da Lingüística Aplicada: Estudos em Homenagem ao Professor Hilário Inácio Bohn. Florianópolis: Insular, 2000.

PERFEITO, A. M. Formação dos professores de língua portuguesa: crise científica. Signum: Estudos da Linguagem, Londrina, n. 6, p. 209-219, 2003.

ROJO, Roxane Helena Rodrigues. Modos de transposição dos PCNs às práticas de sala de aula: progressão curricular e projetos. In:

(Org.) A prática de linguagem em sala de aula: praticando os PCNs. São Paulo: EDUC / Campinas: Mercado de Letras, 2000. p. 27-38. (As faces da lingüística aplicada)

SCHNEUWLY, Bernard. Genres et types de discours: considérations psychologiques et ontogénétiques. In: COLLOQUE DE L'UNIVERSITÉ CHARLES-DE-GAULLE III, Neuchâtel, 1994. Anais... Neuchâtel: Peter Lang, 1994. p.155-173.

SOUZA, Deusa Maria de. Gestos de censura. In: CORACINI, Maria José Rodrigues Faria (Org). Interpretação, autoria e legitimação do livro didático: língua materna e língua estrangeira.. Campinas: Pontes, 1999. p.57- 64.

VEIGA, I. P. A. As dimensões do processo didático na ação docente. In: ROMANOWSKI, J. P.; MARTINS, P. L. O.; JUNQUEIRA, S. R. A . (Orgs.) Conhecimento local e conhecimento universal: pesquisa, didática e ação docente. Curitiba: Champagnat, 2004. p. 13-30.

SCHNEUWLY, Bernard; DOLZ, Joaquim. Os gêneros escolares das práticas de linguagem aos objetos de ensino. In: ROJO, R.; CORDEIRO, G. S. (Orgs.) Gêneros orais e escritos na escola. Campinas: Mercado de Letras, 2004.

; ___ Os gêneros escolares: das práticas de linguagem aos objetos de ensino. Revista Brasileira de Educação, n. 11, p. 516, 1999. 